Microscopy

Coming Events

Due to COVID-19, please check to see if the listed events have been postponed or cancelled.

2021

RMS Event: International Microscopy

Focus Lecture Series

"A brief history of the impact of

Transmission Electron Microscopy on

Materials Science"

Professor Sir Peter Hirsch

October 5, 2021

Virtual

www.rms.org.uk/rms-event-calendar/2021-

events/imfls-professor-sir-peter-hirsch.htm

RMS Event: Imaging ONEWORLD

"Finding the needle in the haystack with

3D correlative light and electron

microscopy"

Dr. Lucy Collinson

October 11, 2021

Virtual

www.rms.org.uk/rms-event-calendar/2021-events/

imaging-oneworld-finding-the-needle.html

flowcytometryUK 2021 (formerly One

Day flowcytometryUK)

November 17-18, 2021

Virtual

www.rms.org.uk/rms-event-calendar/2021

events/flowcytometryuk-2021.html

2021 Gordon Research Conference on Three-Dimensional Electron

Microscopy

October 31-November 5, 2021

Waterville Valley, $\mathrm{NH}$

www.grc.org/three-dimensional-electron-

microscopy-conference/202

\section{Neuroscience 2021 (Hybrid)}

November 8-11, 2021 (virtual)

November 13-16, 2021 (in person)

Chicago, IL and Virtual

http://www.sfn.org/meetings/neuroscience-2021

2021 MRS Fall Meeting \& Exhibit (Hybrid)

November 29-December 2, 2021 (in person)

December 6-8, 2021 (virtual)

Boston, MA and Virtual

www.mrs.org/fall 2021

Cell Bio Virtual 2021

December 1-10, 2021

Virtual

https://www.ascb.org/cellbio2021

2022

Microscopy \& Microanalysis 2022

July 31-August 4, 2022

Portland, OR

www.microscopy.org/events/future.cfm

\section{3}

Microscopy \& Microanalysis 2023

July 24-28, 2023

Minneapolis, MN

www.microscopy.org/events/future.cfm

2024

Microscopy \& Microanalysis 2024

July 28-August 1, 2024

Cleveland, $\mathrm{OH}$

www.microscopy.org/events/future.cfm

\title{
Window to the Brain Allows Observation of Cellular Neural Activity
}

\author{
Stephen W. Carmichael \\ Mayo Clinic, Rochester, MN 55905 \\ carmichael.stephen@mayo.edu
}

Calcium indicators that are genetically encoded, along with transgenic approaches to broadly express these indicators in the mammalian brain in a cell type-specific fashion, have enabled simultaneous imaging of multiple cortical regions. Studies have revealed how neural activity across several regions are coordinated in a variety of brain states and behaviors. For numerous technical reasons these studies have been done mostly in mice while their heads are immobilized. Clever manipulations allow the brain to be imaged during some behaviors, but these behaviors cannot be considered normal. Several head-mounted miniaturized imaging devices have been developed that allow resolution at the cellular level in freely moving animals but only from small fields of view (FOV). A head-mounted imaging device with a relatively large FOV has recently been engineered for useful imaging in rats, but there is a much larger array of genetic tools available for mice than for rats. In an elegant study, Mathew Rynes, Daniel Surinach, and others working in the laboratory of Suhasa Kodandaramaiah introduced the minimScope, a miniature fluorescence microscope capable of simultaneously imaging an $8 \times 10 \mathrm{~mm}^{2}$ FOV with resolutions ranging from about 39 to $56 \mu \mathrm{m}$. This imaging device could be positioned on the head of a freely moving mouse.

Rynes and Surinach, who co-led the effort, specified three criteria that constrained the design of the mini-mScope. First, to permit free behavior and mobility, the overall weight of the device needed to be less than 4 grams, which is about $15 \%$ of the body weight of a mouse. Second, the device needed to image most of the dorsal cortex of the mouse brain. Third, the imaging resolution needed to be sufficient to provide useful images of calcium activity dynamics across the FOV. Briefly, this was accomplished by first performing a large craniotomy over the dorsal cortex of an anesthetized animal, then covering the opening with a 3D-printed transparent shell that was glued in place. Magnets were placed to provide attachment of the mini-mScope before experiments were conducted. Three blue light-emitting diodes (LEDs) and one green LED with appropriate filters were mated with a biconvex lens and a complementary metal oxide semiconductor (CMOS) sensor. The device weighed $3.8 \mathrm{~g}$ and allowed a repertoire of behaviors, including grooming and rearing, indicating that the mice were relatively comfortable with the device in place. Since a single biconvex lens was used to image a convex surface, not all of the surface was in focus, and the optical resolution varied within the FOV.

For some experiments, the team used a transgenic mouse (Thyl-GCaMP6f), which expresses fluorescent reporters of calcium activity in excitatory neurons. Several studies demonstrated that the mini-mScope acquired calcium signals that are comparable to a conventional epifluorescence microscope. Specific stimuli (brief vibrations to a hind limb and flashes of white light in one eye [Figures 1 and 2]) evoked a robust increase in calcium activity in the 

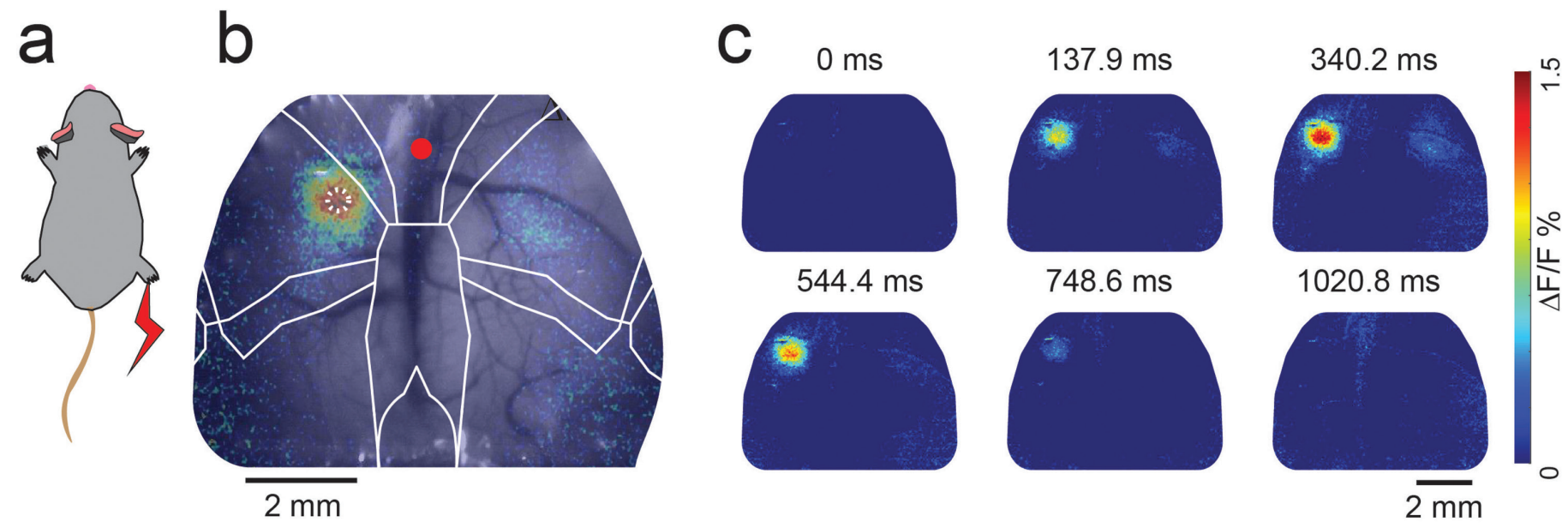

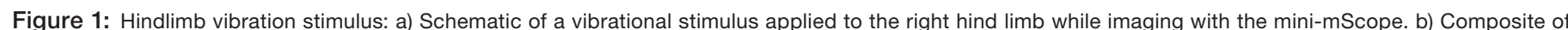

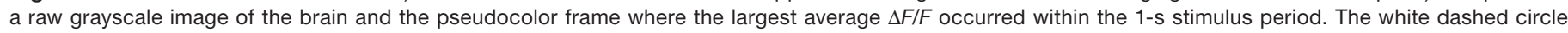
indicates the region of interest with maximum response. c) Montage of average cortical calcium response to the vibration stimulus across time.

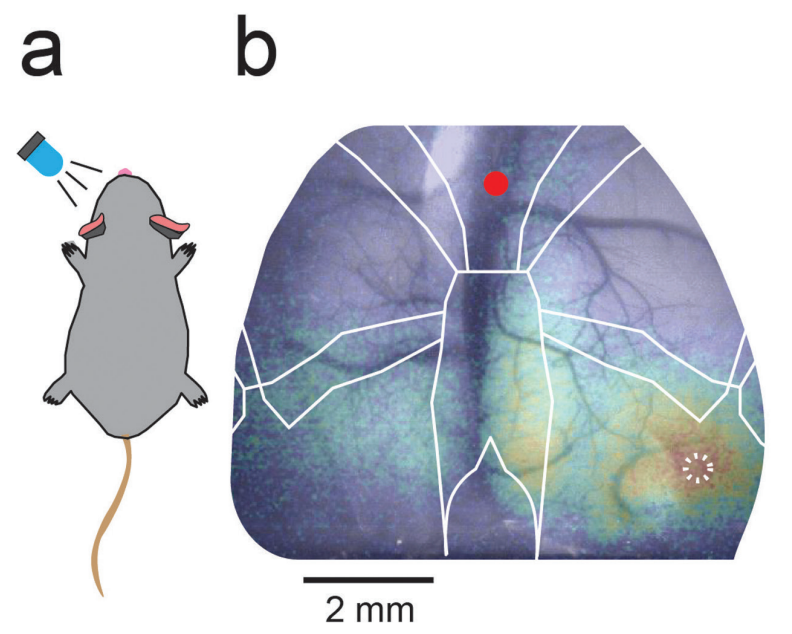

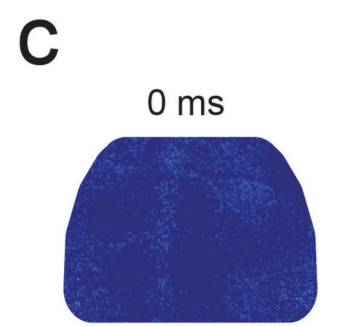
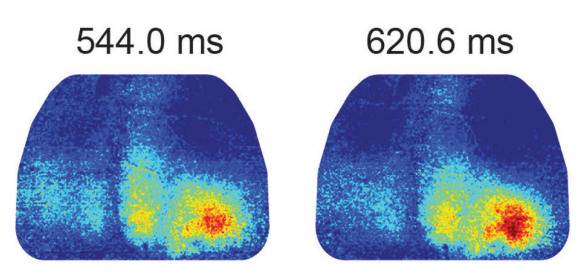

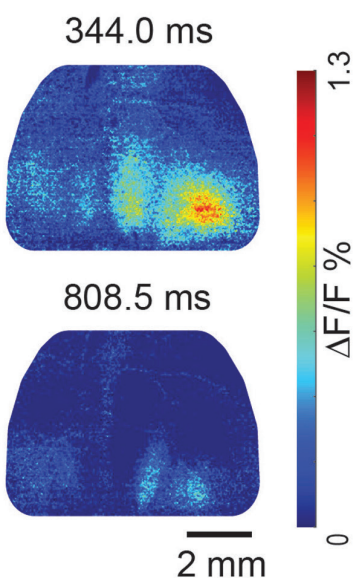

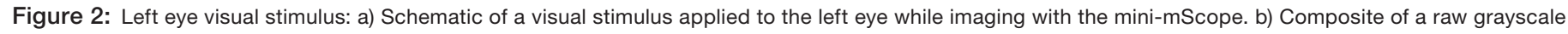

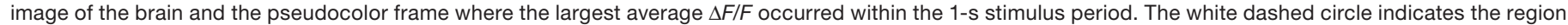
of interest with maximum response. c) Montage of average cortical calcium response to the vibration stimulus across time.

appropriate cortical region with a physiological lag time. Some studies involved solitary mice, and other studies included a companion mouse of the same sex. Numerous results demonstrated the utility of the mini-mScope to study functional connectivity during behaviors that are unique to freely behaving mice.

These and other studies provide proof-of-concept for the use of the mini-mScope with a wide range of transgenic mice for broad expression of genetically encoded calcium indicators. Furthermore, the availability of mouse models of neurodegenerative and neuropsychiatric disorders opens the opportunity to use this unique instrument to examine a wide range of complex behaviors in healthy mice and to observe how these activities may be disrupted in disease states.
Dr. Kodandaramaiah's laboratory is currently developing sensors with increased sensitivity and imaging speed along with other improvements to the mini-mScope. They are also working to expand the FOV to examine other brain regions. These and other efforts are certain to result in a microscope that yields more important revelations of normal and abnormal mammalian brain function.

\section{References}

[1] Rynes et al., Nat Methods, 18 (2021) https://doi. org/10.1038/s41592-021-01104-8.

[2] The author gratefully acknowledges Dr. Suhasa Kodandaramaiah for reviewing this article. 


\section{Transform Your Electron Microscope}

Into a Powerful, Nanoscale Mechanical Testing Chamber
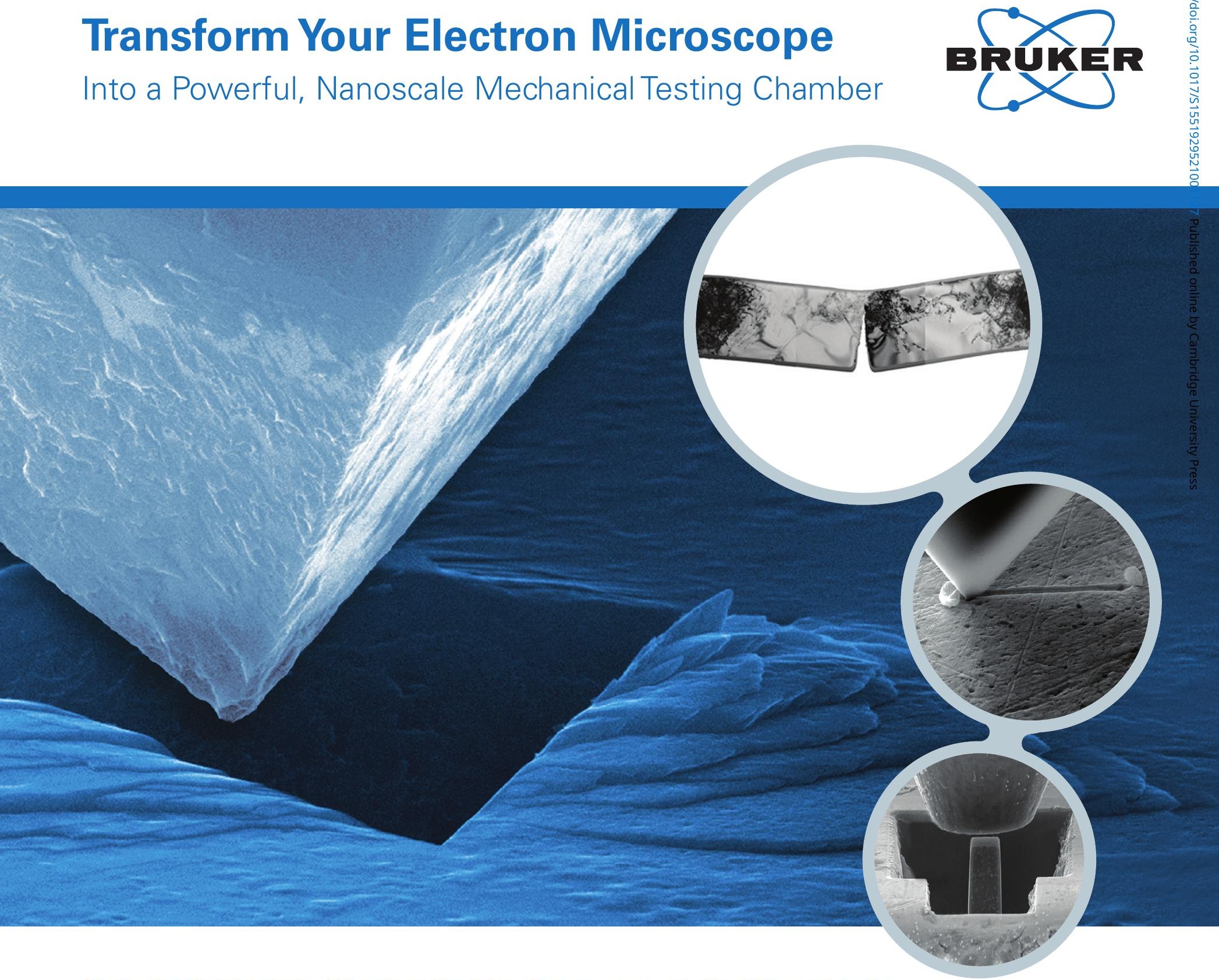

Gain Insights Into Mechanical Performance at the Nanoscale

Bruker's comprehensive suite of in-situ nanomechanical instruments combines powerful electron microscopy with small-scale mechanical testing. Each system is capable of a wide variety of testing modes, enabling unprecedented insights into nanoscale material behavior across the research spectrum.
- Nanoindentation
- NanoTribology
- Microbeam Bending
- High Temperature
- Pillar or Particle Compression
- Electrical
- Tensile Testing
- Dynamic and Fatigue

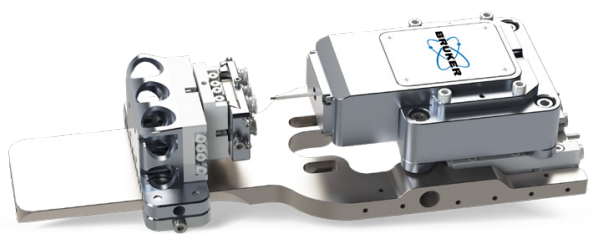

Hysitron PI 89 SEM

Picolndenter

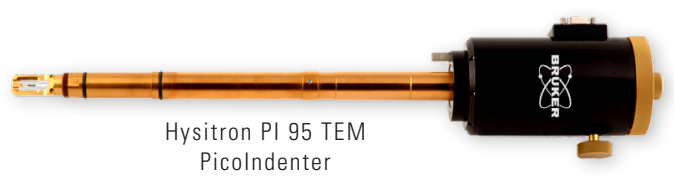

\section{口irita \\ www.bruker.com/picoindenters

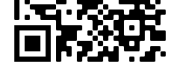

Innovation with Integrity 


\section{First $\gg \gg>$}

\section{HIGH THROUGHPUT SEM System}

\section{Navigator-10T}

(6) times faster than
conventional FE SEMs

Direct electron detection technology and Dual channel imaging (SE\&BSE) Intelligent atlas and cross-scale

(远 Big data intelligent analysis and $\mathrm{Al}$ computing
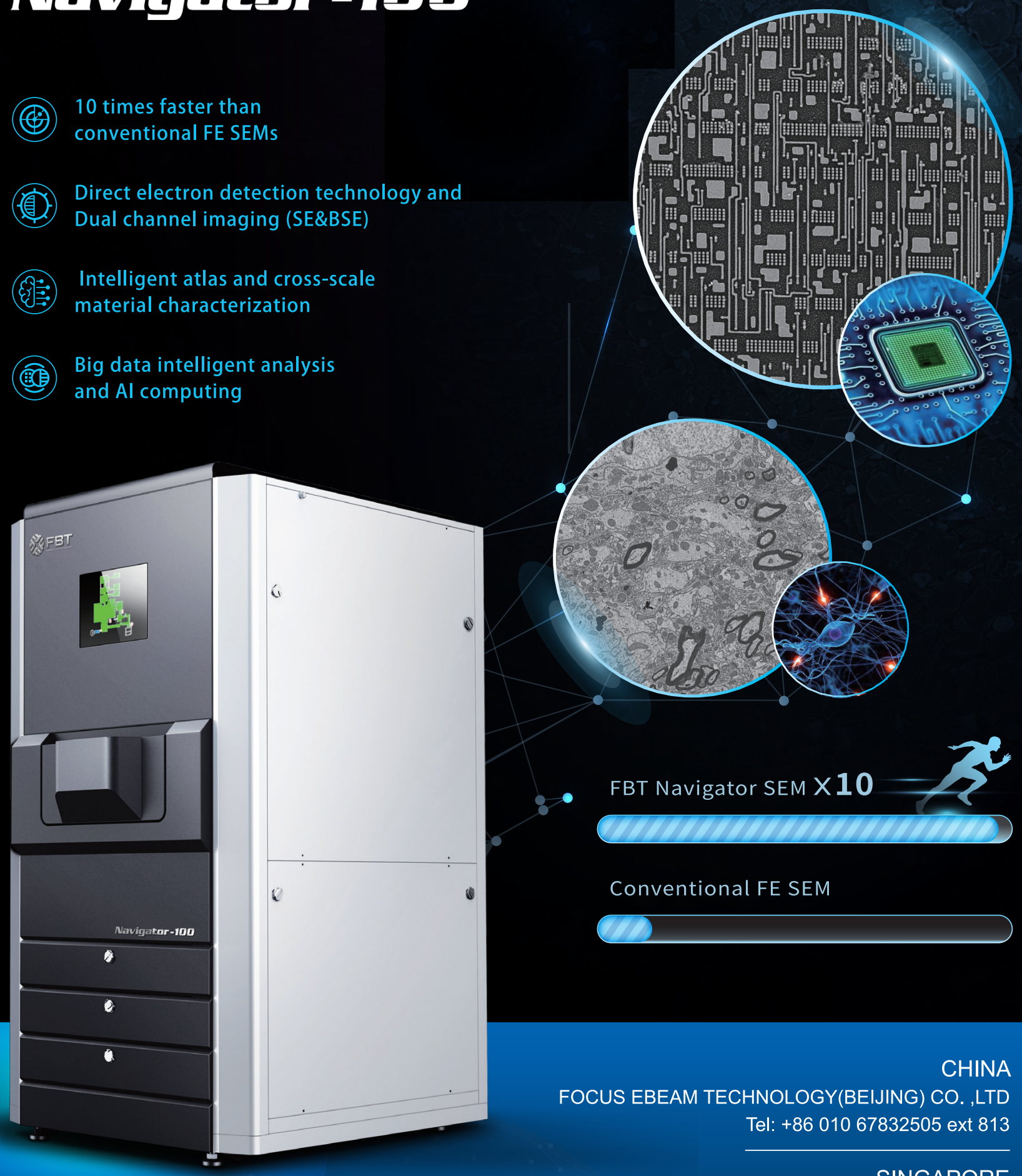

FOCUS EBEAM TECHNOLOGY(BEIJING) CO. ,LTD Tel: +86 01067832505 ext 813 